\title{
Effects of polymorphisms in the bovine growth differentiation factor 9 gene on sperm quality in Holstein bulls
}

\author{
K.Q. Tang1, W.C. Yang ${ }^{1}$, X.X. Zhang ${ }^{2}$ and L.G. Yang ${ }^{1}$ \\ ${ }^{1}$ Key Laboratory of Agricultural Animal Genetics, \\ Breeding and Reproduction of Ministry of Education, \\ Huazhong Agricultural University, Wuhan, China \\ ${ }^{2}$ Beijing Dairy Center, Beijing, China \\ Corresponding author: L.G. Yang \\ E-mail: yangliguo2006@yahoo.com.cn
}

Genet. Mol. Res. 12 (3): 2189-2195 (2013)

Received November 21, 2012

Accepted March 27, 2013

Published July 4, 2013

DOI http://dx.doi.org/10.4238/2013.July.4.1

\begin{abstract}
Members of the transforming growth factor- $\beta$ (TGF $\beta$ ) superfamily are critical regulators of germ cell development that act as extracellular ligands of the signal transduction pathways regulating proliferation, differentiation, apoptosis, and other aspects of cell behavior. Growth differentiation factor 9 (GDF9) is a member of the TGF $\beta$ superfamily that plays a critical role in ovarian follicular development and ovulation rate in females; however, its role in the testis has not been well elucidated. Therefore, in this study we investigated the effects of GDF9 mutations on the quality of fresh and frozen semen of Holstein bulls. Two reported single nucleotide polymorphisms of GDF9, A485TA and $\mathrm{A} 625 \mathrm{C}$, were analyzed in 129 Holstein bulls. Analysis of variance revealed that the A485T polymorphism had significant effects on the acrosome integrity rate $(\mathrm{P}<0.05)$, whereas the $\mathrm{A} 625 \mathrm{~T}$ polymorphism was significantly associated with sperm concentration $(\mathrm{P}<0.05)$. In addition, a significant additive effect on sperm concentration was detected for the A485T polymorphism $(\mathrm{P}<0.05)$, whereas the polymorphisms
\end{abstract}


A485TA and A625C had significant dominant effects on acrosome integrity rate and sperm motility in frozen semen, respectively $(\mathrm{P}<$ 0.05 ). This study is the first to show a significant association of GDF9 with sperm quality traits, and the results implied that GDF9 is involved in the initiation or maintenance of spermatogenesis; however, further verification is needed.

Key words: Holstein bulls; Polymorphism; Sperm quality; Growth differentiation factor 9

\section{INTRODUCTION}

Artificial insemination was the first advanced biotechnological technique applied to improve the reproduction and genetics of farm animals, and it has made an enormous impact on many species worldwide, particularly dairy cattle. However, at the same time, its use has been hindered by the fact that it is very difficult to predict the fertilizing ability of sperm when artificial insemination is used, since it leads to the selection of only those bulls with good reproductive performance (Gadea, 2005). In addition, it is difficult to perform direct selection for semen quality traits, including semen volume per ejaculate, sperm motility, sperm concentration, and so on, because of their low heritability (Rothschild and Bidanel, 1998). It will, therefore, be meaningful to use a candidate gene approach to identify genes that influence semen quality traits. Recently, genes of the hypothalamic-pituitary-testicular axis have been widely studied as candidate marker genes for sperm quality in bulls (Dai et al., 2009; Yang et al., 2011; Sang et al., 2011; Sun et al., 2012); however, only a few studies have examined this for growth factor genes in bulls.

Growth differentiation factor 9 (GDF9), which belongs to the transforming growth factor- $\beta$ (TGF $\beta$ ) superfamily, known as FecG on sheep chromosome 5 (Sadighi et al., 2002), plays a critical role in ovarian follicular development and ovulation rate in females (Elvin et al., 1999; McNatty et al., 2005). In males, GDF9 expression has been detected in the testis (Fitzpatrick et al., 1998; Pennetier et al., 2004; Nicholls et al., 2009); however, its role in the testis has not been well elucidated. Itman et al. (2006) reported that signals from TGF $\beta$ ligands have been implicated in germ cell specification and migration, Sertoli cell proliferation, spermatogonial growth and differentiation, and spermiogenesis. Therefore, Fitzpatrick et al. (1998) and Pennetier et al. (2004) suggested that GDF9 could potentially regulate testicular function, and this concept was supported by Itman et al. (2006, 2008). However, Dong et al. (1996) found that GDF9-knockout males are fertile and show no gross physical or behavioral defects, which indicated that the actions of GDF9 in the testes are not essential for the initiation or maintenance of spermatogenesis. However, the effects of GDF9 on the function of tight junctions, sperm quality, including number, maturation, mobility, and viability, or the circulating concentrations of the key hormones testosterone, follicle-stimulating hormone (FSH), and inhibins have not been analyzed in these knockout models, and a change in any of these parameters could affect male fertility. Nicholls et al. (2009) reported that GDF9 is germ cell-specific factor in the testis, and demonstrated that GDF9 can modulate key functions of Sertoli cells by affecting the function of tight junctions and the expression of inhibin B. To date, no study has reported the effects of GDF9 on sperm quality. Herein, this study aimed 
to elucidate the effects of GDF9 polymorphisms on the quality of fresh and frozen semen in Holstein bulls.

\section{MATERIAL AND METHODS}

\section{Samples and data collection}

All procedures involving animals were approved by the Animal Care and Use Committee of Huazhong Agricultural University. A total of 129 normal mature Holstein bulls were examined in this study; 54 bulls were obtained from the Beijing Dairy Center and 75 bulls were obtained from the Shanghai Bright Dairy \& Food Co., Ltd., China. We collected 40 to 78 ejaculates (more than $88 \%$ of bulls produced more than 70 ejaculates) at intervals of 3 to 6 days from each bull from January to December 2007, and the repeated measurements of sperm quality traits were available. The semen was collected using an artificial vagina. Immediately after collection, the ejaculates were stored at $37^{\circ} \mathrm{C}$ in a water bath to evaluate the quality traits of fresh semen including semen volume per ejaculate [VOL (mL)], sperm motility [MOT $(\%)]$, and sperm concentration [SCON (x $\left.\left.10^{8} \mathrm{~mL}\right)\right]$. The fresh semen was then diluted using glycerol-egg yolk-citrate and made into frozen semen straws. After storage in liquid nitrogen for 5 to 7 days, two straws were randomly obtained from each ejaculate and thawed at $38^{\circ} \mathrm{C}$ for $20 \mathrm{~s}$, and the quality traits of frozen semen were evaluated immediately including sperm motility [FMOT (\%)], acrosome integrity rate [AIR (\%)], and abnormal spermatozoa rate [ASR(\%)] using light microscopy according to the guidelines of the World Health Organization. Genomic DNA was extracted from the sperm using a standard phenol-chloroform extraction protocol. The DNA samples were dissolved in TE buffer $(10 \mathrm{mM}$ Tris- $\mathrm{HCl}, \mathrm{pH} 7.5,1 \mathrm{mM}$ EDTA, $\mathrm{pH}$ 8.0) and stored at $-20^{\circ} \mathrm{C}$ until used.

\section{PCR conditions and genotyping}

We selected two single nucleotide polymorphisms (SNPs), A485TA and A625T (Tang et al., 2013), which are located in intron 1 of the bovine GDF9 gene, to evaluate their effects on the quality traits of sperm from 129 Holstein bulls. Primer sequences (F: 5'-AACAGAAGCC ACCTCTACAAC-3' and R: 5'-CTGGACAAGATGCTAACCTC-3') and reaction conditions for these two polymorphisms were selected according to a previous study (Tang et al., 2013). These polymorphisms were genotyped by sequencing according to Tang et al. (2013).

\section{Statistical analysis}

The allele frequencies of the polymorphisms were determined by direct counting and the Hardy-Weinberg equilibrium was analyzed by the chi-square test using the SAS 8.1 software (SAS Institute Inc., Cary, NC, USA). Pairwise linkage disequilibrium was measured using the online SHEsis software (Shi and He, 2005). Both additive and dominant effects were estimated using models in the REG procedure of SAS 8.1 (Liu, 1998). The associations of GDF9 genotypes with sperm quality traits including VOL, MOT, SCON, AIR, FMOT, and ASR were calculated using the General Linear Model of SAS 8.1, which included the fixed 
effects of age and origin of the bull. Their effects on sperm quality traits were analyzed using the GLM procedure and compared by the Duncan multiple range test (SAS 8.1). Only factors that affected the records significantly $(\mathrm{P}<0.05)$ were fitted in the final statistical model:

$$
y_{i k j}=u+G_{i}+A_{k}+P_{j}+e_{i k j}
$$

where $y_{i k j}$ is the phenotypic value of the traits; $u$ is the population mean; $G_{i}$ is the fixed effect of the genotypes; $A_{k}$ is the fixed effect of age [k=2-10, (1) 2 to 3 years; (2) 4 to 5 years; and (3) 6 to 10 years]; $P_{j}$ is the fixed effect of the origin of bull; and $e_{i k j}$ is the random residual error.

\section{RESULTS}

\section{Genotypic and allelic frequencies}

PCR products were detected using 1.5\% agarose gel electrophoresis. The amplified products were consistent with the target fragments, had good specificity, and could be used directly for genotyping. The frequencies of the g.485A, g.485T, g.625A, and g.625T alleles were $0.717,0.283,0.558$, and 0.442 , respectively, in the population analyzed (Table 1), and these two polymorphisms were in Hardy-Weinberg equilibrium (Table 1). The linkage disequilibrium status of the two SNPs was weak $\left(r^{2}=0.165\right)$; thus, we did not perform further haplotype analysis.

Table 1. Allelic and genotypic frequencies of GDF9 polymorphisms in Holstein bulls.
\begin{tabular}{lcccc}
\hline Locus & Genotype & Genotype frequency & Allele frequency & $\chi^{2}$ value (Hardy-Weinberg equilibrium) \\
\hline A485T & AA (66) & 0.512 & A 0.717 & $0.020(\mathrm{P}>0.05)$ \\
& AT (53) & 0.411 & T 0.283 & $0.005(\mathrm{P}>0.05)$ \\
A625T & TT (10) & 0.078 & & \\
& AA (40) & 0.310 & A 0.558 & \\
& AT (64) & 0.496 & T 0.442 & \\
\hline
\end{tabular}

The values in parentheses are the number of cows.

\section{Association of the genotypes with sperm quality traits}

The results of the association analysis between the GDF9 genotypes and sperm quality traits are given in Tables 2 and 3. For the polymorphic locus 485, bull heterozygous for the g.485AT genotype had a significantly higher AIR $(\mathrm{P}<0.05)$ than those homozygous for the g.485TT genotype (Table 2). For the polymorphic locus 625 , bulls with the g.625TT genotype had significantly higher SCON when compared to those homozygous for the g.625AA ( $\mathrm{P}<$ 0.05 ) genotype (Table 3 ). The additive and dominant effects of the genotypes are shown in Tables 2 and 3, and the A625T polymorphism had a significant additive effect on SCON (P < $0.05)$. Furthermore, the A485TA and A625C polymorphisms had significant dominant effects on AIR and FMOT, respectively $(\mathrm{P}<0.05)$. 


\begin{tabular}{|c|c|c|c|c|c|}
\hline \multirow[t]{2}{*}{ Trait } & \multicolumn{3}{|c|}{ Genotype } & \multirow[t]{2}{*}{ Additive effect } & \multirow[t]{2}{*}{$\overline{\text { Dominant effect }}$} \\
\hline & g.485AA (66) & g.485AT (53) & g.485TT (10) & & \\
\hline VOL $(\mathrm{mL})$ & $6.369 \pm 0.218$ & $6.537 \pm 0.229$ & $6.628 \pm 0.556$ & $0.130 \pm 0.293$ & $-0.019 \pm 0.189$ \\
\hline $\operatorname{SCON}\left(\times 10^{8} \mathrm{~mL}\right)$ & $12.349 \pm 0.360$ & $11.868 \pm 0.425$ & $11.701 \pm 0.944$ & $-0.324 \pm 0.509$ & $0.078 \pm 0.327$ \\
\hline MOT $(\%)$ & $78.00 \pm 1.47$ & $80.525 \pm 1.210$ & $80.363 \pm 2.646$ & $1.179 \pm 1.784$ & $-0.671 \pm 10148$ \\
\hline FMOT $(\%)$ & $40.569 \pm 0.247$ & $40.188 \pm 0.412$ & $39.798 \pm 1.031$ & $-0.386 \pm 0.46$ & $-0.0023 \pm 0.288$ \\
\hline ASR (\%) & $15.656 \pm 0.269$ & $15.224 \pm 0.703$ & $15.894 \pm 0.560$ & $0.119 \pm 0.623$ & $0.275 \pm 0.401$ \\
\hline AIR (\%) & $46.892 \pm 0.637^{\mathrm{ab}}$ & $48.235 \pm 0.771^{\mathrm{a}}$ & $45.098 \pm 0.810^{\mathrm{b}}$ & $-0.567 \pm 1.14$ & $-1.285 \pm 0.733^{*}$ \\
\hline
\end{tabular}

Data are reported as means \pm SE. Values with different letters within the same line indicate significant differences (P $<0.05)$. $*$ Significance level at $\mathrm{P}<0.05 . \mathrm{VOL}=$ semen volume per ejaculate; $\mathrm{SCON}=$ sperm concentration; $\mathrm{MOT}=$ sperm motility; FMOT $=$ frozen sperm motility; $\mathrm{ASR}=$ abnormal spermatozoa rate; $\mathrm{AIR}=$ acrosome integrity rate.

\begin{tabular}{|c|c|c|c|c|c|}
\hline \multirow[t]{2}{*}{ Trait } & \multicolumn{3}{|c|}{ Genotype } & \multirow[t]{2}{*}{ Additive effect } & \multirow[t]{2}{*}{ Dominant effect } \\
\hline & g.625AA (40) & g.625AT (64) & g.625TT (25) & & \\
\hline VOL (mL) & $6.147 \pm 0.298$ & $6.588 \pm 0.220$ & $6.623 \pm 0.253$ & $0.238 \pm 0.219$ & $-0.102 \pm 0.153$ \\
\hline $\operatorname{SCON}\left(\times 10^{8} \mathrm{~mL}\right)$ & $11.570 \pm 0.505^{\mathrm{a}}$ & $12.080 \pm 0.372^{\mathrm{ab}}$ & $13.006 \pm 0.508^{b}$ & $0.718 \pm 0.378^{*}$ & $0.104 \pm 0.265$ \\
\hline MOT (\%) & $79.427 \pm 1.369$ & $78.401 \pm 1.570$ & $81.001 \pm 1.391$ & $0.787 \pm 1.345$ & $0.906 \pm 0.942$ \\
\hline FMOT $(\%)$ & $40.052 \pm 0.501$ & $40.771 \pm 0.332$ & $39.741 \pm 0.368$ & $-0.156 \pm 0.332$ & $-0.437 \pm 0.239^{*}$ \\
\hline $\operatorname{ASR}(\%)$ & $16.113 \pm 0.864$ & $14.892 \pm 0.319$ & $16.061 \pm 0.375$ & $-0.026 \pm 0.463$ & $0.598 \pm 0.324$ \\
\hline AIR $(\%)$ & $47.679 \pm 0.947$ & $47.661 \pm 0.664$ & $45.824 \pm 0.711$ & $-0.927 \pm 0.856$ & $-0.122 \pm 0.602$ \\
\hline
\end{tabular}

Data are reported as means \pm SE. Values with different letters within the same line indicate significant differences $(\mathrm{P}<0.05)$. *Significance level at $\mathrm{P}<0.05$. For abbreviations, see legend to Table 2.

\section{DISCUSSION}

Members of the TGF $\beta$ superfamily are critical regulators of germ cell development (Loveland and Hime, 2005) that act as extracellular ligands of the signal transduction pathways regulating the proliferation, differentiation, apoptosis, and other aspects of cell behavior (Fan et al., 2012). GDF9, which is a member of the TGF $\beta$ superfamily, plays a critical role in ovarian follicular development and ovulation rate in females (Elvin et al., 1999; McNatty et al., 2005); however, the role of GDF9 in the testis has not been well elucidated. Fitzpatrick et al. (1998) and Pennetier et al. (2004) detected expression of GDF9 in the testis, and suggested that it could potentially regulate testicular function. This concept is also supported by the dynamic regulation of BMPRII, ALK5, and ALK6 expression throughout the seminiferous tubules, and the fact that Smad signaling pathways are vital for the control of testis development and spermatogenesis (Itman et al., 2006, 2008; Nicholls et al., 2009). However, Dong et al. (1996) found that GDF9-knockout males are fertile and show no gross physical or behavioral defects, which indicated that the actions of GDF9 are not essential for the initiation or maintenance of spermatogenesis. However, whether the action of GDF9 affects the function of tight junctions, sperm quality, including number, maturation, mobility, and viability, or the circulating concentrations of the key hormones testosterone, FSH, and inhibins has not been analyzed. Furthermore, Nicholls et al. (2009) found that GDF9 can modulate key functions of Sertoli cells by affecting the function of tight junctions and the expression of inhibin B. Therefore, in this study, we aimed to elucidate the effects of GDF9 mutations on sperm quality traits. 
Many mutations have been identified in the exons and introns of sheep or goat GDF9, and found to be significantly associated with litter size or ovulation rate (Hanrahan et al., 2004; Nicol et al., 2009; Barzegari et al., 2010; Polley et al., 2010; Chu et al., 2011). However, studies examining mutations in bovine GDF9 are relatively rare. Tang et al. (2013) first detected the two SNPs A485TA and A625C in GDF9 and reported significant associations with superovulation traits. In the present study, these two SNPs were detected in Holstein bulls. Association analysis revealed that these two polymorphisms had significant effects on sperm quality traits. In addition, a significant additive effect on SCON was detected for the A625T polymorphisms, while the A485TA and A625T polymorphisms had significant dominant effects on AIR and FMOT, respectively. Although these two polymorphisms are located in intron 1 of GDF9, they may affect phenotype, gene expression, and consequent function (Van Laere et al., 2003; Krawczak et al., 2007). Thus, these two polymorphisms may have altered the function of tight junctions or the circulating concentrations of the key hormones testosterone, FSH, and inhibins by affecting signal transduction, and finally influenced sperm quality (Nicholls et al., 2009; Fan et al., 2012).

In conclusion, this study is the first to identify a significant association between GDF9 and sperm quality traits. The results implied that GDF9 is involved in the initiation or maintenance of spermatogenesis, but further verification is needed.

\section{ACKNOWLEDGMENTS}

Research supported by the Huazhong Agricultural University Scientific \& Technological Self-Innovation Foundation (\#2009SC005) and the Earmarked Fund for Modern AgroIndustry Technology Research System (\#nycytx-10).

\section{REFERENCES}

Barzegari A, Atashpaz S, Ghabili K, Nemati Z, et al. (2010). Polymorphisms in GDF9 and BMP15 associated with fertility and ovulation rate in Moghani and Ghezel sheep in Iran. Reprod. Domest. Anim. 45: 666-669.

Chu MX, Yang J, Feng T, Cao GL, et al. (2011). GDF9 as a candidate gene for prolificacy of Small Tail Han sheep. Mol. Biol. Rep. 38: 5199-5204.

Dai L, Zhao Z, Zhao R, Xiao S, et al. (2009). Effects of novel single nucleotide polymorphisms of the FSH beta-subunit gene on semen quality and fertility in bulls. Anim. Reprod. Sci. 114: 14-22.

Dong J, Albertini DF, Nishimori K, Kumar TR, et al. (1996). Growth differentiation factor-9 is required during early ovarian folliculogenesis. Nature 383: 531-535.

Elvin JA, Clark AT, Wang P, Wolfman NM, et al. (1999). Paracrine actions of growth differentiation factor-9 in the mammalian ovary. Mol. Endocrinol. 13: 1035-1048.

Fan YS, Hu YJ and Yang WX (2012). TGF- $\beta$ superfamily: how does it regulate testis development. Mol. Biol. Rep. 39: 4727-4741.

Fitzpatrick SL, Sindoni DM, Shughrue PJ, Lane MV, et al. (1998). Expression of growth differentiation factor-9 messenger ribonucleic acid in ovarian and nonovarian rodent and human tissues. Endocrinology 139: 2571-2578.

Gadea J (2005). Sperm factors related to in vitro and in vivo porcine fertility. Theriogenology 63: 431-444.

Hanrahan JP, Gregan SM, Mulsant P, Mullen M, et al. (2004). Mutations in the genes for oocyte-derived growth factors GDF9 and BMP15 are associated with both increased ovulation rate and sterility in Cambridge and Belclare sheep (Ovis aries). Biol. Reprod. 70: 900-909.

Itman C and Loveland KL (2008). SMAD expression in the testis: an insight into BMP regulation of spermatogenesis. Dev. Dyn. 237: 97-111.

Itman C, Mendis S, Barakat B and Loveland KL (2006). All in the family: TGF- $\beta$ family action in testis development. Reproduction 132: 233-246. 
Krawczak M, Thomas NS, Hundrieser B, Mort M, et al. (2007). Single base-pair substitutions in exon-intron junctions of human genes: nature, distribution, and consequences for mRNA splicing. Hum. Mutat. 28: 150-158.

Liu BH (1998). Statistical Genomics, Linkage, Mapping and QTL Analysis. CRC Press, LLC, Boca Raton, 404-409.

Loveland KL and Hime G (2005). TGFbeta superfamily members in spermatogenesis: setting the stage for fertility in mouse and Drosophila. Cell Tissue Res. 322: 141-146.

McNatty KP, Juengel JL, Reader KL, Lun S, et al. (2005). Bone morphogenetic protein 15 and growth differentiation factor 9 co-operate to regulate granulosa cell function in ruminants. Reproduction 129: 481-487.

Nicholls PK, Harrison CA, Gilchrist RB, Farnworth PG, et al. (2009). Growth differentiation factor 9 is a germ cell regulator of Sertoli cell function. Endocrinology 150: 2481-2490.

Nicol L, Bishop SC, Pong-Wong R, Bendixen C, et al. (2009). Homozygosity for a single base-pair mutation in the oocytespecific GDF9 gene results in sterility in Thoka sheep. Reproduction 138: 921-933.

Pennetier S, Uzbekova S, Perreau C, Papillier P, et al. (2004). Spatio-temporal expression of the germ cell marker genes MATER, ZAR1, GDF9, BMP15, and VASA in adult bovine tissues, oocytes, and preimplantation embryos. Biol. Reprod. 71: 1359-1366.

Polley S, De S, Brahma B, Mukherjee A, et al. (2010). Polymorphism of BMPR1B, BMP15 and GDF9 fecundity genes in prolific Garole sheep. Trop. Anim. Health Prod. 42: 985-993.

Rothschild MF and Bidanel JP (1998). Biology and Genetics of Reproduction. In: The Genetics of the Pig (Rothschild MF, ed.). CAB International, Wallingford, Oxon, 313-343.

Sadighi M, Bodensteiner KJ, Beattie AE and Galloway SM (2002). Genetic mapping of ovine growth differentiation factor 9 (GDF9) to sheep chromosome 5. Anim. Genet. 33: 244-245.

Sang L, Du QZ, Yang WC, Tang KQ, et al. (2011). Polymorphisms in follicle stimulation hormone receptor, inhibin alpha, inhibin bata A, and prolactin genes, and their association with sperm quality in Chinese Holstein bulls. Anim. Reprod. Sci. 126: 151-156.

Shi YY and He L (2005). SHEsis, a powerful software platform for analyses of linkage disequilibrium, haplotype construction, and genetic association at polymorphism loci. Cell Res. 15: 97-98.

Sun LP, Du QZ, Song YP, Yu JN, et al. (2012). Polymorphisms in luteinizing hormone receptor and hypothalamic gonadotropin-releasing hormone genes and their effects on sperm quality traits in Chinese Holstein bulls. Mol. Biol. Rep. 39: 7117-7123.

Tang KQ, Yang WC, Li SJ and Yang LG (2013). Polymorphisms of the bovine growth differentiation factor 9 and their associated with superovulation performance in Chinese Holstein cows. Genet. Mol. Res. 12: 390-399.

Van Laere AS, Nguyen M, Braunschweig M, Nezer C, et al. (2003). A regulatory mutation in IGF2 causes a major QTL effect on muscle growth in the pig. Nature 425: 832-836.

Yang WC, Tang KQ, Yu JN, Zhang CY, et al. (2011). Effects of MboII and BspMI polymorphisms in the gonadotropin releasing hormone receptor (GnRHR) gene on sperm quality in Holstein bulls. Mol. Biol. Rep. 38: 3411-3415. 